Proceedings of the 2016 Winter Simulation Conference

T. M. K. Roeder, P. I. Frazier, R. Szechtman, E. Zhou, T. Huschka, and S. E. Chick, eds.

\title{
DISCRETE SIMULATION SOFTWARE RANKING - a Top list of the Worldwide most Popular and Used Tools
}

\author{
Luís M. S. Dias \\ António A. C. Vieira \\ Guilherme A. B. Pereira \\ José A. Oliveira \\ Department of Production and Systems // ALGORITMI Research centre \\ University of Minho \\ Braga, 4710-057, PORTUGAL \\ http://www.dps.uminho.pt < \{lsd, antonio.vieira,gui,zan $\} @$ dps.uminho.pt $>$ \\ Phone: +351253604764/+351934774014 Fax: +351253604741
}

\section{KEYWORDS}

Survey, review, comparison, assessment, simulation languages, discrete simulation, packages, commercial software, ranking, popularity.

\section{ABSTRACT}

This paper documents a work on all-purpose discrete event simulation tools evaluation. Selected tools must be suitable for process design (e.g. manufacturing or services industries). Rather than making specific judgments of the tools, authors tried to measure the intensity of usage or presence in different sources, which they called "popularity". It was performed in several different ways, including occurrences in the WWW and scientific publications with tool name and vendor name. This work is an upgrade to the same study issued 5 years ago (2011), which in its turn was also an upgrade of 10 years ago (in 2006). It is obvious that more popularity does not assure more quality, or being better to the purpose of a simulation tool; however, a positive correlation may exist between them. The result of this work is a short list, of 19 commercial simulation tools, with probably the nowadays' most relevant ones.

\section{INTRODUCTION}

Most of scientific works related to tools comparison analyze only a small set of tools and usually evaluating several parameters separately, avoiding to make a final judgment, due to it's subjectivity.

Simulation languages have been replaced by simulation software packages/tools. High market prices of simulation tools in the past decades, added to other factors like: ease of construction of a simulation tool; the emerging graphics facilities; the wide field of applications and the absence of strong standards or languages; lead to a large, or may be too large, tools offer (Dias, 2005).

Thus, for instance, in the Industrial Engineering Magazine (1993/July) there is a list of 45 commercial simulation software products. The sixth biannual edition of simulation software compiled by James J. Swain in 2003 identified about 60 commercial simulation products, 55 in 2005, 48 in 2009, 43 in 2013, 55 in 2015 (Swain, 1991-2015). The annual 2004 SCS edition - "M\&S Resource Directory" lists 60 simulation products (Klee, 2004). In the "Simulation Education Homepage" (Simulation tools list by William Yurcik) there were more than 200 simulation products, including non commercial tools.

This work started with Swain's list, removing non discrete event simulation environments, and adding some tools found in more than one list sources.

As aforementioned, this tools comparison was performed previously in 2006 and 2011, and is now extended with more parameters and relevant changes are discussed. 


\section{Dias, Vieira, Pereira and Oliveira}

In this scenario of such a large simulation tools' offer it is unfeasible to perform a consistent experiment. The comparison, based on features or characteristics is also very difficult or non conclusive because most of them have similar features lists.

The measure here called "popularity" was the way that we found to overcome those difficulties, identifying the tools that are potentially the best or most used. Choosing a popular simulation tool ma bring benefits in two different perspectives:

- If you are a company, it is easier to find simulation specialists with know-how on a popular tool;

- If you are a simulation specialist, it is easier to find companies working with a popular tool.

The second way includes educational purposes because students should be the future simulation specialists. Nevertheless, popularity should never be used as a unique parameter for simulation tools selection. If so, new tools, would never gain market share - and this is a generic risk, not a simulation particularity. Therefore, the popularity may be seen as a significant "blind" factor to be used in conjunction with direct evaluation mechanisms like features comparison and experimentation.

Product names in this paper are trademarks or registered trademarks of their respective owners.

\section{METHODOLOGY}

Our evaluation method, in order to identify a short list containing the most popular or important tools, was essentially based in the intensity or level of presence on the following categories:

- Winter Simulation Conference scientific publications;

- Document database oriented sites;

- Presence in selected reviews, surveys, comparisons, among other selected sources.

- Social networks;

- WWW (Internet);

- Web searches' trend (Delta) over the last 5 years (new). It is calculated based on the number of search results on each of the last 5 years - percentage - in relation to the total number of search results. The final value of this category is obtained by multiplying the obtained percentage with the assigned weight.

\subsection{Technique}

For the purpose of measuring the web-presence, Google searching engine was used. The reasons are:

- It is the most used search engine on the Web $+65 \%$ of searching actions in 2015 (https://search enginewatch.com/sew/news/2391446/googles-search-share-goes-to-yahoo-comscore-reports).

- Google owns different sources of relevant information (e.g. Books, YouTube, Maps, Translator);

- It supports a VBA (Visual Basic for Applications) methods for getting the number of search results, therefore, for this project we also developed a procedure - Excel macro - for automatically updating data in an Excel sheet.

- It supports restricted search to specific domains (e.g. scribd.com, books.google.com, linkedin.com, facebook.com).

- In nowadays Google has in fact become a synonym of the word "search" (https://searchenginewatch.com/sew/how-to /2048976/major-search-engines-directories)

\subsection{Factors Description and Tunning}

We used 50 parameters/factors. This represents an increase of 10 new parameters, in comparison to the previous 2011 paper. Nonetheless, some parameters were excluded for several reasons, for instance docstoc.com was closed, therefore the number of new parameters is actually higher than 10 - around 15 . All parameters can be consulted in Table 2. Each category comprises a set of specific parameters. For each tool we additionally defined the two following labels: 


\section{Dias, Vieira, Pereira and Oliveira}

- "Tool" represents the search string containing the name of the simulation tool, the word "simulation" and some additional words to avoid finding pages out of the topic due to common English words used as tools names. (e.g. "Arena", "Extend", "Quest" etc).

- "Vendor" represents the search string containing the name of the simulation tool vendor.

"T" is also used as abbreviation of "Tool" and "TV" as "Tool"+"Vendor".

Factors values, representing the number of occurrences, vary from units to millions. The sum of all of them together would lead to irrelevant factors mixed with absorbent factors. To reduce the impact of different orders of magnitude, the uses of mathematical functions were studied in order to "control" big numbers, although keeping relative differences. Square and cubic root, Natural and ten base logarithms were the evaluated possibilities.

After an extensive iterative and empiric process, the cubic root was chosen, once it was proven to consider both small and big numbers adequately - see Figure 1 (cubic root $(x)=x^{\wedge} 1 / 3$ ). The use of a cubic root of a number in place of the number itself, is the same as comparing the volume of cubes, using only the value of their width. The use of this function is not solidly supported, notwithstanding that the use of a different one would not lead to significant changes in the relative position of the tools.

\begin{tabular}{|r|r|r|r|r|}
\hline 1000000 & 1000 & 100 & 14 & 6 \\
\hline 100000 & 316 & 46 & 12 & 5 \\
\hline 10000 & 100 & 22 & 9 & 4 \\
\hline 1000 & 32 & 10 & 7 & 3 \\
\hline 100 & 10 & 5 & 5 & $\mathbf{2}$ \\
\hline 10 & 3 & 2 & 2 & 1 \\
\hline 1 & 1 & 1 & 0 & 0 \\
\hline
\end{tabular}

Figure 1 Possible Functions to Factors Adjustment

\section{SEARCH RESULTS ANALYSIS}

All parameters were divided into each of the aforementioned categories. Table 2 shows the description of all parameters. The results obtained for each parameter will now be analyzed, separately for each category. Figure 2 indicates the factor weights applied for each string related to WSC, whether T and TV, as well the obtained raw results and the same results, considering the factor applied.

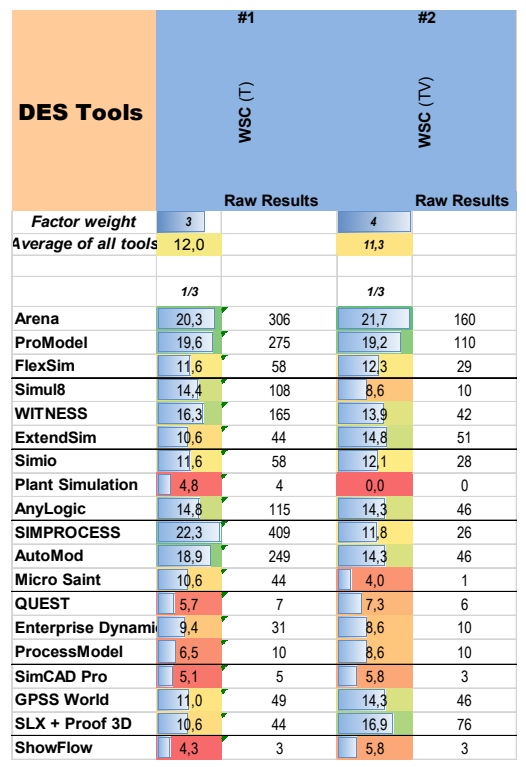

Figure 2: Factor values for WSC T and WSC TV 


\section{Dias, Vieira, Pereira and Oliveira}

As the figure suggests, the results obtained for each parameter of WSC (T and TV) vary - almost all the tools have higher values in WSC T, which is expected since its search string is less restricted however, multiplying the cubic root of the search results for a factor weight of each parameter, the parameter factor values were obtained. The same was done for all parameters. In this case, weights 3 and 4 were respectively assigned to WSC T and WSC TV search strings thus, in some cases, while raw search results may be higher in TV than in T, the pondered values may not. Arena, ProModel, AutoMod and SIMROCESS are the tools with the most presence in the WSC and Plant Simulation, QUEST, SimCAD Pro and ShowFlow are the ones with the least WSC presence. Figure 3 to Figure 7 show the results for the remaining sets of parameters.

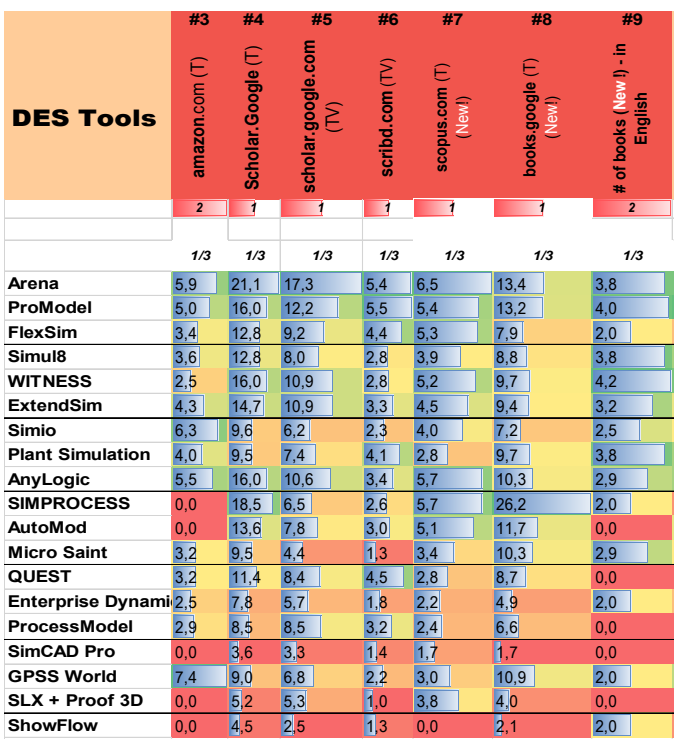

Figure 3: Documents digital libraries parameters

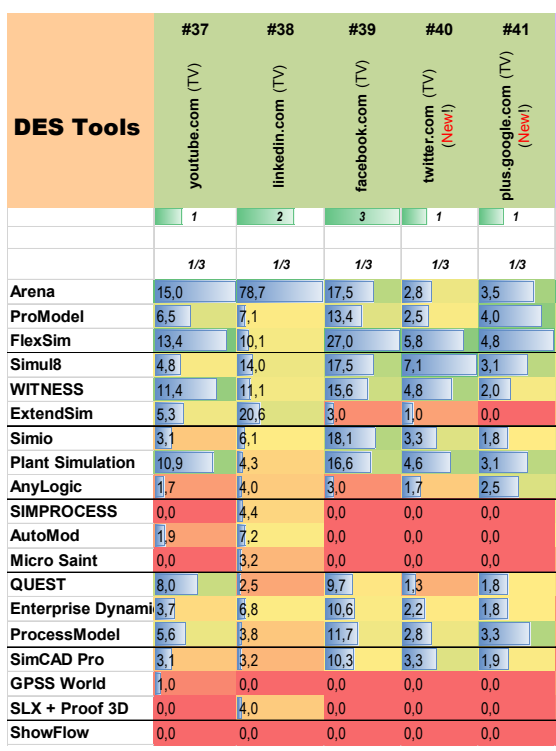

Figure 4: Social networks parameters
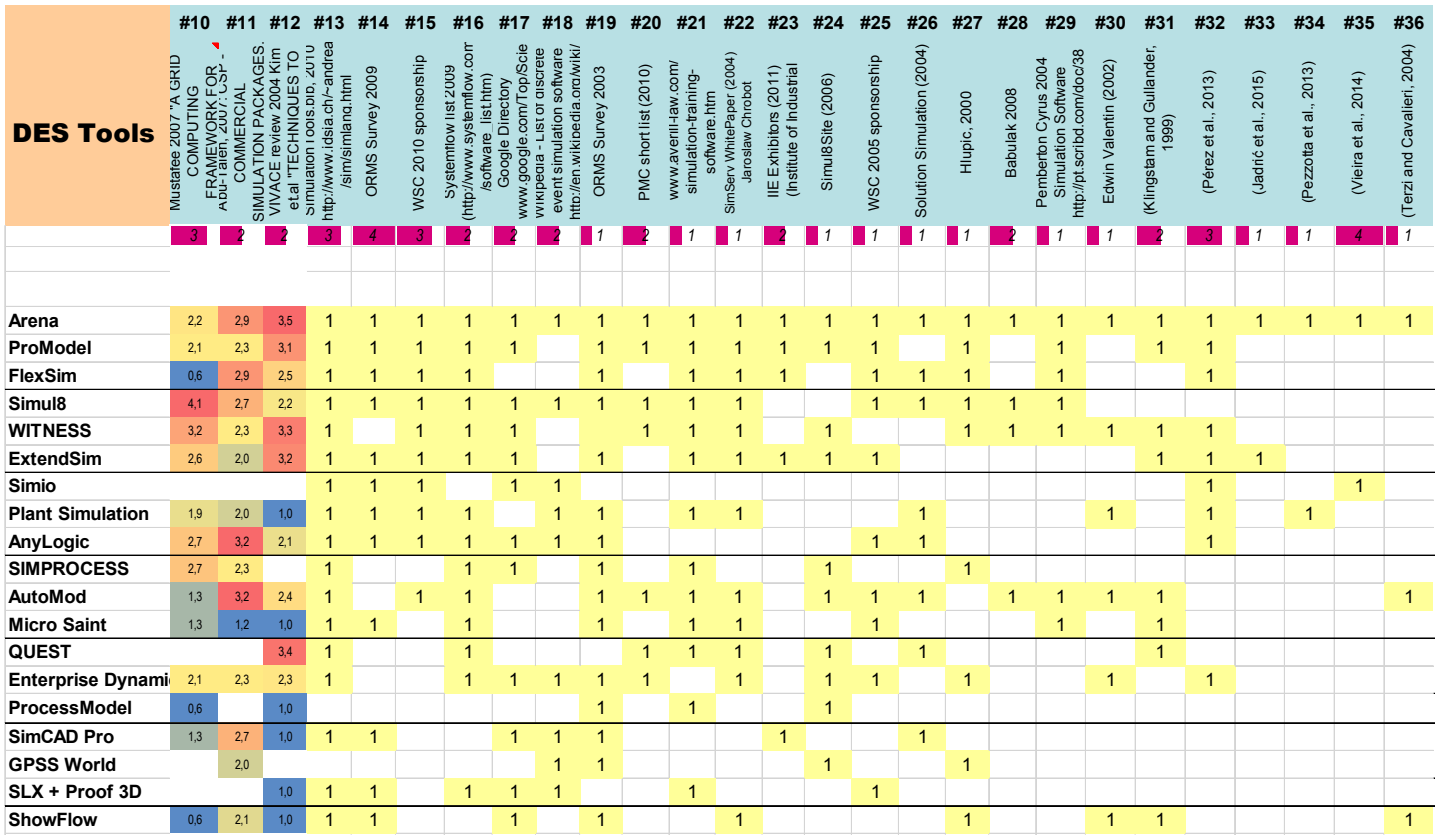

Figure 5: Parameters of selected reviews 


\section{Dias, Vieira, Pereira and Oliveira}

Figure 3 indicates the parameters categorized as documents databases. As the figure indicates, three new parameters, in comparison to the former 2011 ranking, were added: Scopus, Google Books and number of published books related to the tool. Arena, ProModel and SIMPROCESS are the tools with most presence in these documents databases. In their turns, SimCAD Pro, SLX + Proof 3D and Showflow are the ones with the lowest factor parameter values.

Figure 5 shows the selected reviews, comparison, surveys, among other sources. This list contains the items from the former 2011 ranking and six more, four of which were published post 2011, making a total of 27 parameters. The first three columns refer to relevant reviews with some kind of tools evaluation and their results were used here with proportional scoring. All the others are just binary scores when the tool name is referenced in the specified sources. Considering all the obtained average factor parameters values, Arena, ProModel and Simul8 obtained the best results, whilst ProcessModel and GPSS obtained the lowest values.

Figure 4 shows the obtained factor values for the social networks parameters. As can be seen, despite the increasing importance of social networks in nowadays, particularly in spreading several kinds of information, the lack of significant presence of some tools in this frame should be stressed, c.f. Micro Saint, GPSS World and ShowFlow. On the other hand, Arena and FlexSim are the tools with the most presence in social networks. In comparison to the former 2011 ranking, twitter and google plus social networks were added.

The case of social networks is a particular case, since some tools purposely opt to have a higher presence on certain social networks, disregarding the remaining, which affects the overall rate obtained in this ranking. For instance, ExtendSim has a higher presence in YouTube and Linkedin, disregarding the remaining and Simio has a greater presence in facebook. Figure 6 and Figure 7 shows the obtained factor values for the parameters of Google search results.

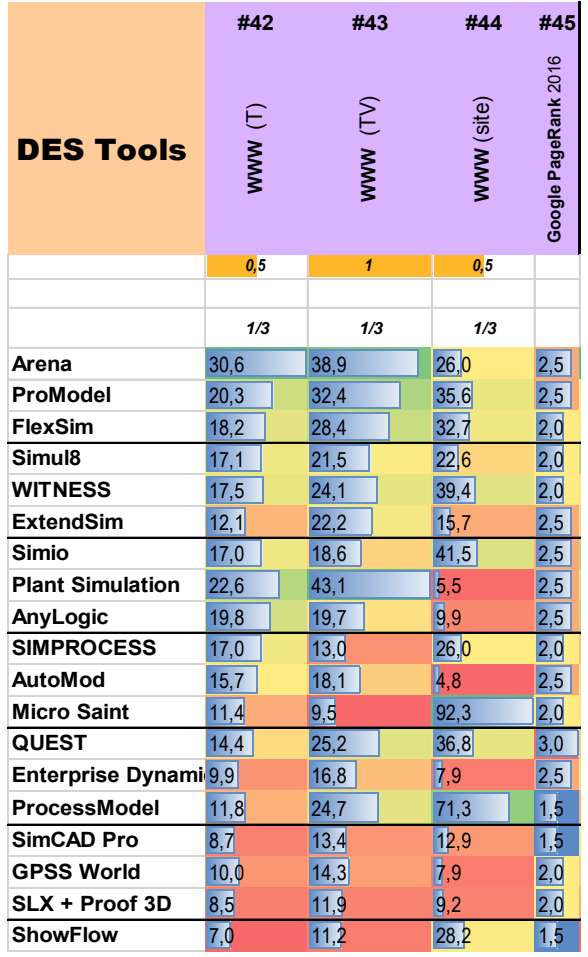

Figure 6: Parameters of Google search results

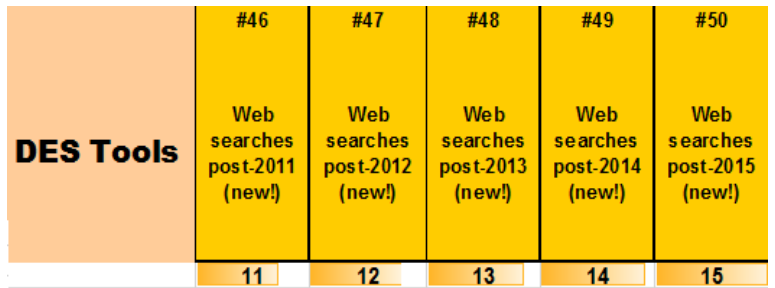

\begin{tabular}{llllll}
\hline Arena & 3,29 & 3,34 & 3,21 & 2,84 & 1,93 \\
\hline ProModel & 1,16 & 1,12 & 0,95 & 0,76 & 0,51 \\
\hline FlexSim & 1,35 & 1,33 & 1,21 & 1,01 & 0,67 \\
\hline Simul8 & 2,11 & 1,78 & 1,61 & 1,34 & 0,97 \\
\hline WITNESS & 1,10 & 1,01 & 0,88 & 0,68 & 0,39 \\
\hline ExtendSim & 1,56 & 1,39 & 1,05 & 0,76 & 0,44 \\
\hline Simio & 2,16 & 2,06 & 1,89 & 1,52 & 1,08 \\
\hline Plant Simulation & 1,65 & 1,61 & 1,66 & 1,42 & 1,03 \\
\hline AnyLogic & 1,98 & 1,83 & 1,37 & 0,89 & 0,38 \\
\hline SIMPROCESS & 0,82 & 0,90 & 0,78 & 0,48 & 0,44 \\
\hline AutoMod & 1,06 & 1,12 & 0,76 & 0,29 & 0,16 \\
\hline Micro Saint & 1,08 & 1,19 & 1,20 & 0,48 & 0,11 \\
\hline QUEST & 0,91 & 0,99 & 0,91 & 0,63 & 0,45 \\
\hline Enterprise Dynami & 1,40 & 1,56 & 1,47 & 0,97 & 0,51 \\
\hline ProcessModel & 0,69 & 0,77 & 0,74 & 0,52 & 0,32 \\
\hline SimCAD Pro & 1,30 & 1,52 & 1,20 & 0,89 & 0,33 \\
\hline GPSS World & 0,88 & 0,98 & 0,85 & 0,46 & 0,31 \\
\hline SLX+ Proof 3D & 0,64 & 0,70 & 0,65 & 0,39 & 0,33 \\
\hline ShowFlow & 0,06 & 0,05 & 0,06 & 0,03 & 0,01
\end{tabular}

Figure 7: Parameters of Web search trend results (Delta)

As Figure 6 suggests, Arena, ProModel, Micro Saint and ProcessModel are the tools with higher Google search results. On the other hand, SimCAD Pro, GPSS and SLX obtained the lowest values. 


\section{Dias, Vieira, Pereira and Oliveira}

As Figure 7 suggests, the reason for the high factor weights assigned to each of these properties is that the percentage of the searches of more recent years, in comparison to the results without time restrictions is too low. Therefore, and since a greater emphasis on these parameters was to be given, higher factor weight values were assigned. As the results indicate, Arena and Simio are the tools with the best result for these parameters, indicating that these are the 2 tools with most growth in search results over the last 5 years. While Arena is a much older simulation tool, it should also be stressed that it continues to grow as it obtained the highest value for these parameters. ShowFlow got the lowest value.

\section{OBTAINING THE FINAL CLASSIFICATIONS OF THE RANKING}

The final score each tool obtained in each category of parameters is illustrated in Figure 8.

In the first place, the values of each parameter, for each tool, were summed. In order to neutralize different categories scales, those values have been normalized, as follows. The average and standard deviations of the obtained results were calculated (A and B). The upper ceiling $(\mathrm{C})$ corresponds to $\mathrm{A}+1.5 * \mathrm{~B}$. Each category score is then calculated dividing its sum by $\mathrm{C}$, and multiplying it by 10 , truncating the maximum value to 10. As result, all categories scores are between 0 and 10 . These values are the indicated in Figure 8. To obtain the final score, a pondered average between the assigned weights to the categories and its values was performed.

Like in all rankings, also in this one there are groups of tools that are closely ranked and others that are isolated, regarding their classifications. In fact, apart from Arena - by far the best classification tool with 9,9 out of 10 points - and from the last four tools - SimCAD Pro, GPSS World, SLX + Proof 3D and ShowFlow - the remaining tools are closely ranked. In fact, three classification clusters can be identified: third cluster ranging from position 10 to 15; second cluster from 6 to 9; and first cluster from 2 to 5 . The tools in these positions are closely ranked and, as such, their final classification is highly dependent on the weights assigned to each separately parameter and to the categories themselves. Regarding the low results that some of the tools achieved in the social network parameters, it can be explained by the fact that some of these tools opt for specific social networks. For instance, even though ExtendSim has a low overall social network result, by analysing Figure 4 it is clear that this simulation tool opts for specific social networks - in this case the tool has a presence in YouTube and Linkedin above the average. To better analyze the impact each category as on the simulation tools, the chart on Figure 9 was created.

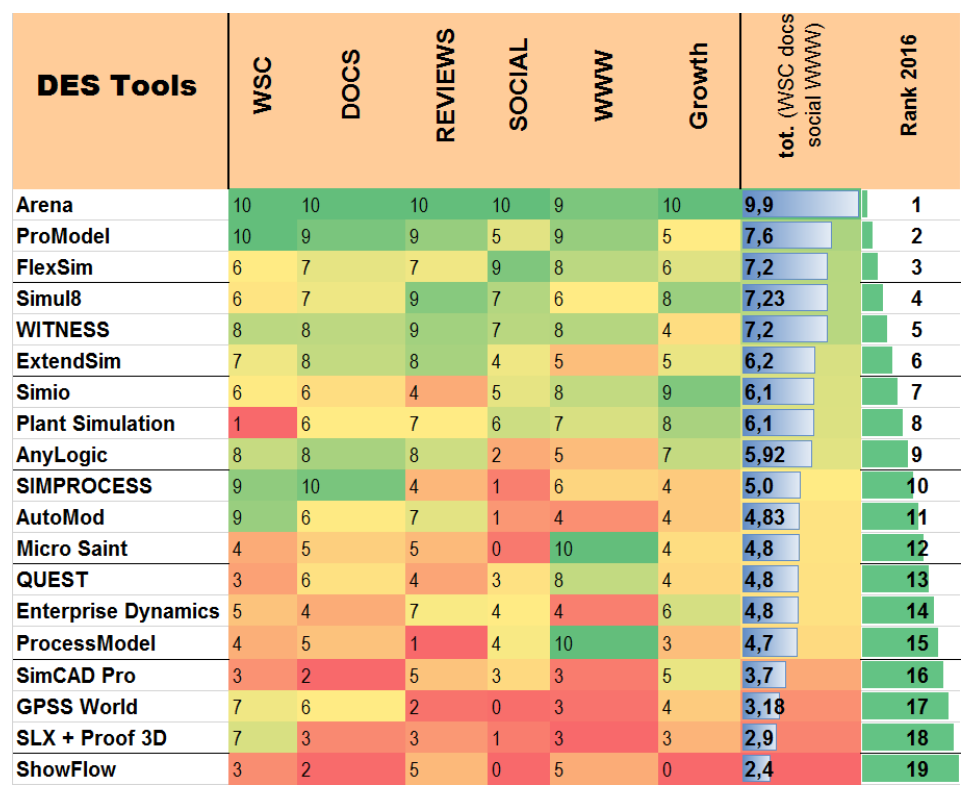

\begin{tabular}{|c|c|c|c|c|c|}
\hline DES Tools & 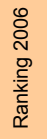 & 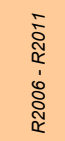 & 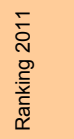 & $\begin{array}{l}\frac{n}{\pi} \\
\stackrel{0}{\Phi} \\
\stackrel{n}{n} \\
. \subseteq\end{array}$ & 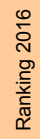 \\
\hline Arena & 1 & $\Rightarrow 0$ & $1 \Rightarrow$ & 0 & 1 \\
\hline ProModel & 2 & $\Rightarrow-2$ & $4 \Rightarrow$ & 2 & 2 \\
\hline FlexSim & 10 & 203 & $7 \approx$ & 4 & 3 \\
\hline Simul8 & 7 & 等 5 & $2 \Leftrightarrow$ & -2 & 4 \\
\hline WITNESS & 5 & $\Rightarrow 2$ & $3 \Rightarrow$ & -2 & 5 \\
\hline ExtendSim & 6 & $\Rightarrow 0$ & $6 \Rightarrow$ & 0 & 6 \\
\hline Simio & & NEW & 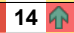 & 7 & 7 \\
\hline Plant Simulation & 17 & 4 8 & $9 \Leftrightarrow$ & 1 & 8 \\
\hline AnyLogic & 15 & 苗 10 & $5 y$ & -4 & 9 \\
\hline SIMPROCESS & 4 & $\sqrt{3}-8$ & $12 \Rightarrow$ & 2 & 10 \\
\hline AutoMod & 3 & $\sqrt{-5}$ & 8 & -3 & 11 \\
\hline Micro Saint & 14 & $\Rightarrow-1$ & $15 \approx$ & 3 & 12 \\
\hline QUEST & 8 & $\Rightarrow-2$ & 10 빈 & -3 & 13 \\
\hline Enterprise Dynamics & 16 & 5 & 11 빈 & -3 & 14 \\
\hline ProcessModel & 12 & $\sum-1$ & $13 \Leftrightarrow$ & -2 & 15 \\
\hline SimCAD Pro & - & - & $16 \Rightarrow$ & 0 & 16 \\
\hline GPSS World & 18 & $\sum-1$ & $19 \Leftrightarrow$ & 2 & 17 \\
\hline SLX + Proof 3D & 11 & b-6 & $17 \Rightarrow$ & -1 & 18 \\
\hline ShowFlow & - & - & $18 \Rightarrow$ & -1 & 19 \\
\hline
\end{tabular}

Figure 8: Final score of each tool and Ranking comparison 2006-2011 
Dias, Vieira, Pereira and Oliveira

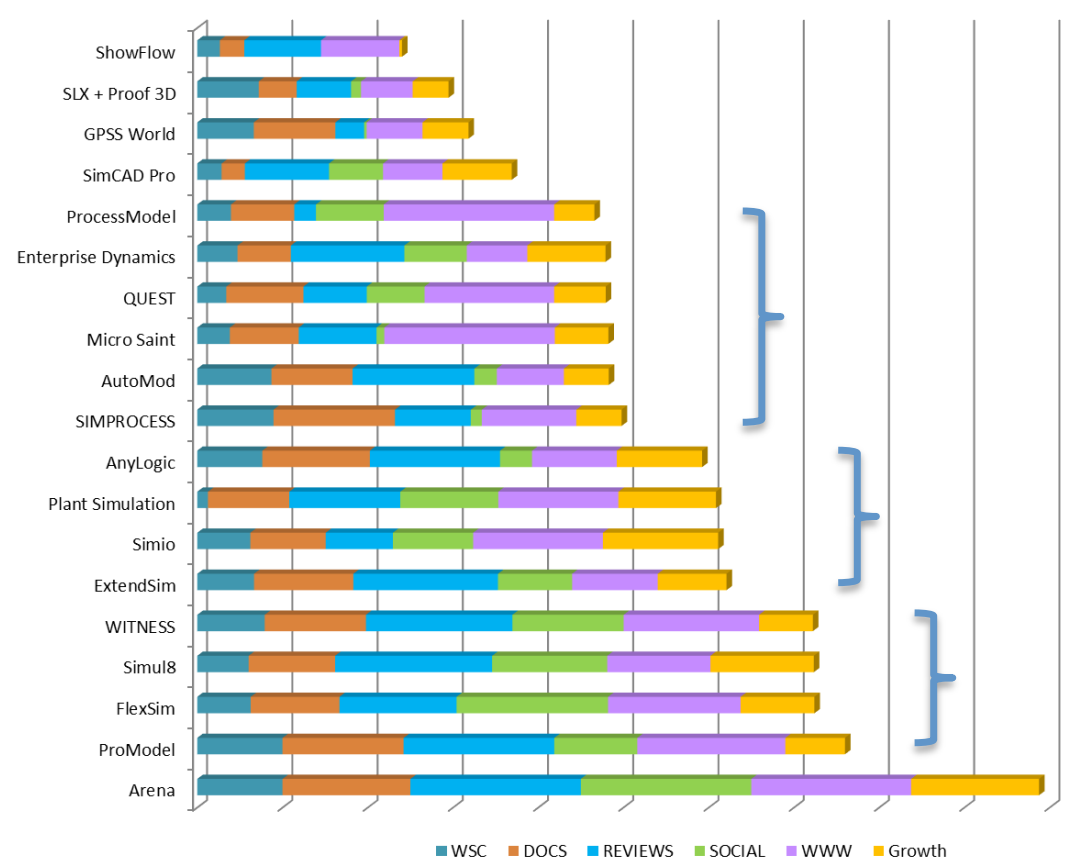

Figure 9 Scoring distribution

\section{COMPARISON WITH FORMER 2006 AND 2011 RANKINGS}

In this ranking we introduced the trend in web searches. Moreover, some social networks parameters were introduced, as well as some documents databases parameters, including the number of books. Figure 8 shows tools rankings evolution from 2006 (Dias et.al 2007) to 2011 (Dias et al., 2011) and to 2016.

Whilst Arena constantly keeps its number 1 position, ProModel regained its second position and FlexSim keeps its climb to the first places, now achieving the podium. The climb of ProModel and FlexSim made Simul8 drop to the fourth place, however it is still in a noteworthy position. In its turn, ExtendSim keeps its sixth place - the same place the tool was in 2011 and even in 2006 and Simio registers the biggest climb this year's top -7 places. AnyLogic had also registered a huge climb in the former 2011 ranking - 10 places - however in this ranking the tool dropped 4 places. On the other hand, AutoMod keeps dropping in the top, after having achieved the podium in 2006.

\section{CONCLUSIONS}

This paper documents an updated version of a ranking of discrete simulation tools (Dias et al., 2006 and 2011). This list was created based on the subjective evaluation of a parameters set. Different parameters may be used alternatively with different weights producing other results. Even though this subjectivity, we believe that the Top 10 "popular" discrete simulation commercial tools are included in this list of 19 simulation tools. As well as it is most likely that this list includes the top 10 "most used" and "best" contemporary simulation tools. Moreover, the strengths and weaknesses of each tool, regarding the considered categories, were also analyzed.

In measuring popularity some other relevant parameters could be considered like the number of sold licences in the industry area (with a company size factor) or used at universities for education purposes. Although it is quite difficult to reliably collect these types of data.

As a conclusion of this research study, we were able to identify a simulation tool in the first place (Arena), stands out from the remaining tools. Thereafter, a first cluster of simulation tools appear (ProModel, FlexSim, Simul8 and WITNESS), followed by a second cluster (ExtendSim, Simio, PlantSimulation and AnyLogic) and a third cluster (Simprocess, Automod, Micro Saint, QUEST, 


\section{Dias, Vieira, Pereira and Oliveira}

Enterprise Dynamics and Process Model). Despite the dependency of these rankings to the subjective weights of each category, the authors were able to observe that the mentioned clusters would still be the same. The difference would be that tools would change rankings inside each cluster.

The contexts of the simulation tools, whether in the academic environment or in the industry is in constant change and thus this study should be regularly updated. Hence an upgraded version of this ranking should be developed.

\section{ACKNOWLEDGMENTS}

This work has been co-supported by SI I\&DT project in joint-promotion $\mathrm{n}^{\mathrm{o}} 36265 / 2013$ (HMIEXCEL) and by FCT Fundação para a Ciência e Tecnologia - project: PEst-OE/EEI/UI0319/2014.

\section{REFERENCES}

Abu-Taieh, 2007: CSP - COMMERCIAL SIMULATION PACKAGES. I.J. of SIMULATION Vol. 8 No 2. ISSN 1473-804x (http://ducati.doc.ntu.ac.uk/uksim/journal/Vol-8/No-2/paper-7.pdf)

Babulak B and Wang M. 2008. Discrete Event Simulation: State of the Art. International Journal of Online Engineering (iJOE), Vol 4, No 2 (2008) ISSN: 1861-212

Dias, L.; Rodrigues, A.; Pereira, G. 2005. "An activity oriented visual modelling language with automatic translation to different paradigms", In Proceedings of the 19th European Conference On Modelling And Simulation (ECMS 2005), Riga, Letónia. Ed. Yury Mercuryev et al. Junho de 2005. pp. 452-461

Dias, Luís S. 2005. Automatic Interactive Modelling of Simulation. Ph.D. Thesis. (written in Portuguese Modelação Automática Interactiva de Simulação). Department of Production and Systems Engineering University of Minho, Portugal.

Dias, L., Pereira, G., Rodrigues, A., 2006. A Shortlist of the Most 'Popular' Discrete Simulation Tools, In (M. Becker, H. Szczerbicka, eds.) Proc. ASIM 2006 - 19th Symposium on Simulation Technique, SCS.(Hanover, Germany) pp. 159-163. 12-14

Dias, L.; Pereira, G.; Rodrigues, A. 2007. A Shortlist of the Most "Popular" Discrete Simulation Tools. Journal SNE Simulation News Europe., April 2007, pp 33-36. ISSN 0929-2268.

Dias, L., G. Pereira, P. Vik, and J. A. Oliveira, 2011, Discrete simulation tools ranking: a commercial software packages comparison based on popularity, Conference, Venice, Italy, June 2011: 5-10., Eurosis.

Hlupic, Vlatka and Ray J. Paul. 1999. Guidelines for selection of manufacturing simulation software. In IIE Transactions on Design and Manufacturing, 31(1). 21-29.

Hlupic, Vlatka. 2000. Simulation software: an operational research society survey of academic and industrial users. In Proceedings of the 2000 Winter Simulation Conference, ed. J. A. Joines, R. R. Barton, K. Kang e P. A. Fishwick. 1676-1683. Piscataway, New Jersey: Institute of Electrical and Electronics Engineers.

Jadrić, M., M. Ćukušić, and A. Bralić, 2015, Comparison of discrete event simulation tools in an academic environment: Croatian Operational Research Review, v. 5, p. 203-219.

Klee, Harold (ed.). 2004. Modeling and Simulation Resource Directory. In Modeling and Simulation, Directory Issue 2004, vol. $3 \mathrm{n}^{\circ} 4$, Oct-Dec. The Society for Modeling and Simulation International (SCS), San Diego, USA. ISBN 1-56555-297-0 ISSN 1537-7733

Klingstam, P., and P. Gullander, 1999, Overview of simulation tools for computer-aided production engineering: Computers in Industry, v. 38, p. 173-186.

Law, A. M. and McComas, M. G. 2002. Simulation optimization: simulation-based optimization. In Proceedings of the 34th Conference on Winter Simulation: Exploring New Frontiers (San Diego, California, December 08 - 11, 2002). Winter Simulation Conference. 41-44. portal.acm.org/citation.cfm?id=1030461

Mustafee N. 2007. A grid computing framework for commercial simulation packages. Brunel University, West London, PhD Thesis.bura.brunel.ac.uk/bitstream/2438/4009/1/Fulltext(Thesis).pdf

ORMS Simulation Tools List (www.lionhrtpub.com/orms/surveys/Simulation/Simulation.html)

Recent Sponsors of the Institute of Industrial Engineers Conference (www.iieannual.org/IndustryTracks.htm)

Pezzotta, G., R. Pinto, F. Pirola, P. Gaiardelli, and S. Cavalieri, 2013, A Critical Evaluation and Comparison of Simulation Packages for Service Process Engineering: XVIII Summer School Francesco Turco. A Challenge for the Future: the role of industrial engineering in a global sustainable economy. 


\section{Dias, Vieira, Pereira and Oliveira}

Pérez, J. B., J. M. Corchado, J. Fähndrich, P. Mathieu, A. Campbell, M. C. Suarez-Figueroa, A. Ortega, E. Adam, E. M. Navarro, and R. Hermoso, 2013, Trends in Practical Applications of Agents and Multiagent Systems: 11th International Conference on Practical Applications of Agents and Multi-Agent Systems, Springer International Publishing.

Swain, James J. 2009-2015. Simulation Software Survey. OR/MS Today magazine from Institute for Operations Research and the Management Sciences (INFORMS). Lionheart Publishing. 1991-2009. www.lionhrtpub.com/orms/surveys/Simulation/Simulation.html

Solution Simulation 2004, Site of the conference - the sponsors list: (http://www.simsol.org/2004\%20files /SimSol\%20onsite\%202004\%20revised.pdf).

Sponsors of the Winter Simulation Conference 2005 (www.wintersim.org/exhibits.htm)

Site of the INFORMS simulation society (www.informs-sim.org)

Site with scientific simulation publications of the Institute for Operations Research and the Management Science Simulation Society. Contains the Winter Simulation Conference Publications (www.informs-sim.org)

Terzi, S., and S. Cavalieri, 2004, Simulation in the supply chain context: a survey: Comp. in industry, v. 53, p. 3-16.

Vieira, A., L. Dias, G. Pereira, and J. Oliveira, 2014, Comparison of Simio and Arena simulation tools, ISC, University of Skovde, Skovde, Sweden.

\section{BIOGRAPHY}

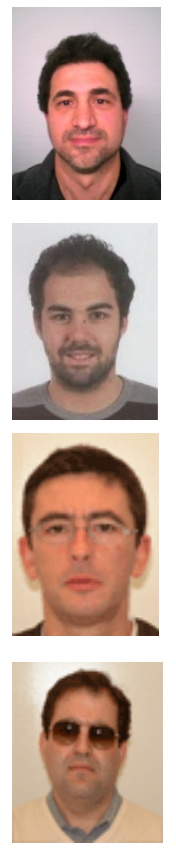

Luís M S Dias was born in 1970 in Vila Nova de Foz Côa, Portugal. He graduated in Computer Science and Systems Engineering in the University of Minho, Portugal. He holds an MSc degree in Informatics Engineering and a PhD degree in Production and Systems Engineering from the University of Minho, Portugal. His main research interests are Simulation, Systems Performance, Operational Research and Systems Visual Modeling.

António A C Vieira was born in 1989 in Vila Nova de Famalicão, Portugal. He graduated in Informatics Engineering in the University of Minho. He holds a MSc degree in Systems Engineering at the University of Minho. He is making his doctoral studies in Advances Engineering Systems for Industry at the University of Minho. His main research interests are Simulation, Systems Performance, Operational Research and Programming Languages.

Guilherme A B Pereira was born in 1961 in Porto, Portugal. He graduated in Industrial Engineering and Management in the University of Minho, Portugal. He holds an MSc degree in Operational Research and a PhD degree in Manufacturing and Mechanical Engineering from the University of Birmingham, UK. His main research interests are Operational Research and Simulation.

José A Oliveira was born 1966 in Matosinhos, Portugal. He studied Mechanical Engineering at the University of Porto, Portugal. He graduated with a Ph.D. in Production and Systems Engineering at University of Minho, Portugal. His main research interests are Optimization with Heuristic Methods in Systems Engineering.

\section{APPENDIX Table 1 Factors Description}

$\begin{array}{lll}\# & \text { Factor Name } & \text { Description } \\ \mathbf{1} & \text { WSC "only Tool" } & \begin{array}{l}\text { Occurrences of "Tools" in www.informs-sim.org. (Institute for Operations Research and Management Science - } \\ \text { Simulation Society) (includes all Winter Simulation Conference - papers 1997-2011April) }\end{array} \\ \mathbf{2} & \text { WSC "TV"= "Tool+Vendor" } & \begin{array}{l}\text { Occurrences of "Tools" + "Vendor" in www.informs-sim.org (same source as \#1)) } \\ \text { Occurrences of "Tools" + "Vendor" in site:amazon.com }\end{array} \\ \mathbf{4} & \text { amazon.com } & \text { Occurrences of "Tools" in site:Scholar.Google } \\ \mathbf{5} & \text { Scholar.Google "T" } & \text { Occurrences of "Tools" + "Vendor" in site:Scholar.Google } \\ \mathbf{6} & \text { Scholar.Google } & \text { Occurrences of "Tools" + "Vendor" in site:scribd.com } \\ \mathbf{7} & \text { scopus.com } & \text { Occurrences of "Tools" in site:scopus.com } \\ \mathbf{8} & \text { books.google T } & \text { Occurrences of "Tools" in site:books.google.com } \\ \mathbf{9} & \text { \# of books } & \text { Number of books published in english } \\ \mathbf{1 0} & \text { Mustafee } 2007 & \text { Mustafee N. 2007 "A Grid Computing Framework For Commercial Simulation Packages". Brunel University, West } \\ & & \text { London, PhD Thesis. bura.brunel.ac.uk/ bitstream/2438/4009/1/Fulltext(Thesis).pdf }\end{array}$




\section{Dias, Vieira, Pereira and Oliveira}

\begin{tabular}{|c|c|c|}
\hline \# & Factor Name & Description \\
\hline 11 & Abu-Taieh, 2007 & $\begin{array}{l}\text { Abu-Taieh. 2007. Commercial Simulation Packages - CSP. I.J. of SIMULATION Vol. } 8 \text { No 2. ISSN 1473-804x } \\
\text { (http://ducati.doc.ntu.ac.uk/uksim/journal/Nol-8/No-2/paper-7.pdf) }\end{array}$ \\
\hline 12 & VIVACE review 2004 & VIVACE review: "Techniques to Model the Supply Chain in an Extended Enterprise", Kim et.al, 2004. \\
\hline 13 & SimulationTools.bib 2010 & $\begin{array}{l}\text { List with Simulation Tools with Short Description. By Andrea Emilio Rizzoli. SimulationTools.bib, } 2010 \\
\text { http://www.idsia.ch/ andrea/sim/simlang.html }\end{array}$ \\
\hline 14 & ORMS Survey 2009 & $\begin{array}{l}\text { Swain J. 2009. Simulation Software Survey. OR/MS. Institute for Operations Research and the Management Sciences } \\
\text { (INFORMS). Lionheart Publishing. 1991-2009. www.lionhrtpub.com /orms/surveys/Simulation/Simulation.html }\end{array}$ \\
\hline 15 & WSC 2010 sponsorship & Sponsors of the Winter Simulation Conference 2010 (Memory registered in year 2011) \\
\hline 16 & Systemflow list 2009 & Simulation Software List - System flow Simulations, Inc. (2005-2009)http://www.systemflow.com/software_list.htm \\
\hline 17 & Google's Simul. S/W & $\begin{array}{l}\text { Google Directory of Simulation Software } \\
\text { www.google.com/Top/Science/Software/Simulation/ }\end{array}$ \\
\hline 18 & Wikipedia - List of Simul.S/W & $\begin{array}{l}\text { Wikipedia - List of discrete event simulation software } \\
\text { http://en.wikipedia.org/wiki/List_of_discrete_event_simulation_software }\end{array}$ \\
\hline 19 & ORMS Survey'03 & Swain J. 2003. (See Factor \#14) \\
\hline 20 & PMC short list (2010) & List of the simulation tools where the PMC Company have competency (http://www.pmcorp.com/sim_services.shtm) \\
\hline 21 & www.averill-law.com & Averill-law list of simulation training software: (www.averill-law.com/simulation-training-software.htm) \\
\hline 22 & SimServ WhitePaper (2004) & $\begin{array}{l}\text { Sim-Serv organization white paper about simulation tools. Jaroslaw Chrobot. 2004. (http://www.sim- } \\
\text { serv.com/wg_doc/WG1_White_Paper_discussion.pdf) }\end{array}$ \\
\hline 23 & IIE Exhibitors (2011) & $\begin{array}{l}\text { Exhibitors of the IIE Conference } \\
\text { (http://www.iienet2.org/annual2/details.aspx?id=6790) }\end{array}$ \\
\hline 24 & Simul8Site (2006) & Brooks homepage (Simul8) identification of concurrency (www.simul8.com/products/webdemo.htm) \\
\hline 25 & WSC 2005 & Sponsors of the Winter Simulation Conference 2005 (Memory registered in year 2006) \\
\hline 26 & Solution Simulation 2004 & $\begin{array}{l}\text { Sponsors of the } \quad \text { conference } \\
\text { http://www.simsol.org/2004\%20files/SimSol\%20onsite\%202004\%20revised.pdf }\end{array}$ \\
\hline 27 & Hlupic, 2000 & $\begin{array}{l}\text { Hlupic V. 2000. Simulation software: an operational research society survey of academic and industrial users. In (J. } \\
\text { Joines et. al., eds.) Proc. WSC 2000. (Piscataway, New Jersey), IEEE, 1676-1683. }\end{array}$ \\
\hline 28 & Babulak 2008 & $\begin{array}{l}\text { Babulak B and Wang M. 2008. Discrete Event Simulation: State of the Art. International Journal of Online Engineering } \\
\text { (iJOE), Vol 4, No } 2 \text { (2008) ISSN: } 1861-2121\end{array}$ \\
\hline 29 & P. Cyrus 2004 Sim. S/W & $\begin{array}{l}\text { Simulation Software List by Pemberton Cyrus, } 2004 \\
\text { http://pt.scribd.com/doc/38056975/Simulation-Software-2004-05-28 }\end{array}$ \\
\hline 30 & Edwin Valentin (2002) & $\begin{array}{l}\text { Tools systematic evaluation based on experimentation (Valentin, 2002). (http://www.tbm.tudelft.n } \\
\text { /webstaf/edwinv/SimulationSoftware/index.htm) }\end{array}$ \\
\hline 31 & $\begin{array}{l}\text { Klingstam and Gullander, } \\
1999\end{array}$ & $\begin{array}{l}\text { Klingstam, P., and P. Gullander, 1999, Overview of simulation tools for computer-aided production engineering } \\
\text { Computers in Industry, v. } 38, \text { p. } 173-186 \text {. }\end{array}$ \\
\hline 32 & Pérez et al., 2013 & $\begin{array}{l}\text { Pérez, J. B., J. M. Corchado, J. Fähndrich, P. Mathieu, A. Campbell, M. C. Suarez-Figueroa, A. Ortega, E. Adam, E. M. } \\
\text { Navarro, and R. Hermoso, 2013, Trends in Practical Applications of Agents and Multiagent Systems: } 11 \text { th International } \\
\text { Conference on Practical Applications of Agents and Multi-Agent Systems, Springer International Publishing. }\end{array}$ \\
\hline 33 & Jadri et al., 2015 & $\begin{array}{l}\text { Jadri, M., M. ukuši , and A. Brali , 2015, Comparison of discrete event simulation tools in an academic environment } \\
\text { Croatian Operational Research Review, v. } 5 \text {, p. 203-219. }\end{array}$ \\
\hline 34 & Pezzotta et al., 2013 & $\begin{array}{l}\text { Pezzotta, G., R. Pinto, F. Pirola, P. Gaiardelli, and S. Cavalieri, 2013, A Critical Evaluation and Comparison of } \\
\text { Simulation Packages for Service Process Engineering: XVIII Summer School Francesco Turco. A CHALLENGE FOR } \\
\text { THE FUTTURE: the role of industrial engineering in a global sustainable economy. }\end{array}$ \\
\hline 35 & Vieira et al., 2014 & $\begin{array}{l}\text { Vieira, A., L. Dias, G. Pereira, and J. Oliveira, 2014, Comparison of Simio and Arena simulation tools, ISC, University of } \\
\text { Skovde, Skovde, Sweden. }\end{array}$ \\
\hline $\begin{array}{l}36 \\
37\end{array}$ & $\begin{array}{l}\text { Terzi and Cavalieri, } 2004 \\
\text { youtube.com }\end{array}$ & $\begin{array}{l}\text { Terzi, S., and S. Cavalieri, 2004, Simulation in the supply chain context: a survey: Computers in industry, v. 53, p. 3-16. } \\
\text { Occurrences of "Tools" + "Vendor" in site:youtube.com }\end{array}$ \\
\hline 38 & linkedin.com & Occurrences of "Tools" + "Vendor" in site:linkedin.com \\
\hline 39 & facebook.com & s of "Tools" + "Vendor" in site:facebook.com \\
\hline 40 & twitter.com & Occurrences of "Tools" + "Vendor" in site:twitter.com \\
\hline 41 & plus.google & Occurrences of "Tools" + "Vendor" in site:plus.google.com \\
\hline 42 & WWW only "Tool" & $\begin{array}{l}\text { Number of web pages with "Tools"+"simulation"(the "simulation" string was used to count only the internet pages in the } \\
\text { simulation area) }\end{array}$ \\
\hline 43 & WWW "TV" & Number of web pages with "Tools"+"Vendor"+"simulation" \\
\hline 44 & "Site" in WWW & Occurrences of vendor's site address in WWW \\
\hline 45 & Google PageRank'16 & Google "PageRank" (Google automatic evaluation about page importance). Current value (2016). \\
\hline 46 & Web searches post 2011 & Factor of the ratio of post 2011 searches in comparison to searches without restrictions. \\
\hline 47 & Web searches post 2012 & Factor of the ratio of post 2012 searches in comparison to searches without restrictions. \\
\hline 48 & Web searches post 2013 & Factor of the ratio of post 2013 searches in comparison to searches without restrictions. \\
\hline 49 & Web searches post 2014 & Factor of the ratio of post 2014 searches in comparison to searches without restrictions. \\
\hline 50 & Web searches post 2015 & Factor of the ratio of post 2015 searches in comparison to searches without restrictions. \\
\hline
\end{tabular}

